\title{
PENGEMBANGAN LEMBAR KERJA MAHASISWA (LKM) BERBASIS KONTEKSTUAL PADA MATA KULIAH KIMIA ANORGANIK
}

\author{
Erviyenni, Elva Yasmi \\ Laboratorium Program Studi Pendidikan Kimia FKIP Universitas Riau \\ E-mail : erviyenni@gmail.com.
}

\begin{abstract}
Abstrak
Penelitian pengembangan perangkat bertujuan untuk mengembangkan Lembar Kerja Mahasiswa berbasis Contextual yang valid, praktis, dan efektif untuk pembelajarn Kimia Anorganik. Metode penelitian yang digunakan adalah penelitian pengembangan (development research). Penelitian dilaksanakan dalam enam bulan dan terdiri dari empat tahap, yaitu tahap pendefinisian (define), perancangan (design), pengembangan (develop), pendesiminasian (desseminate). Penelitian baru sampai kepada tahap pengembangan. Data penelitian dikumpulkan melalui lembar penilaian yang diisi oleh validator. Hasil penelitian menunjukkan bahwa Lembar Kerja Mahasiswa behasis Contextual yang dikembangkan untuk pembelajaran materi reduksi oksidasi, unsure dan senyawa kompleks telah memenuhi kriteria valid dari segi format, teknis maupun isi.
\end{abstract}

Kata Kunci: Pengembangan, Lembar Kerja Mahasiswa, Contextual, Kimia Anorganik

\begin{abstract}
The development of research aimed at developing Contextual-based Student Worksheet valid, practical, and effective for learning chemistry inorganic. The method used is development research (development research). The research was conducted in six months and consists of four stages, namely the definition phase (define), the design (design), development (develop), pendesiminasian (desseminate). New research to the development stage. The research data were collected through evaluation sheets filled in by the validator. The results showed that the Student Worksheet based Contextual of learning material developed for the reduction of oxidation, elements and complex compounds have valid criteria in terms of format, technical and content.
\end{abstract}

Keywords: Development, student Worksheet, contextual, Inorganic chemistry

\section{PENDAHULUAN}

Perkuliahan yang dilaksanakan di Program Studi Pendidikan Kimia sudah mengacu kepada pembelajaran yang berpusat kepada mahasiswa (Student centered Learning,SCL), dimana mahasiswa senantiasa dilibatkan dalam memperoleh dan mengolah informasi terutama dalam mempresentasikan materi perkuliahan. Bruner menyatakan bahwa tiga proses berlangsung bersamaan ketika siswa belajar yaitu memperoleh informasi, mentransformasi informasi dan menguji relevansi serta 
ketepatan pengetahuan dengan kehidupan sehari-hari. Dosen pengampu matakuliah berupaya menggunakan berbagai pendekatan, strategi dan model pembelajaran yang berpusat pada mahasiswa agar mahasiswa dapat mencapai tujuan pembelajaran seperti yang sudah dijabarkan dari kompetensi-kompetensi.dasar sesuai silabus

Mata kuliah Kimia Anorganik merupakan salah satu matakuliah wajib bagi mahasiswa di program studi pendidikan kimia, dengan alokasi waktu 3 SKS, mahasiswa dituntut agar memiliki kompetensi dapat memahami., melatih mahasiswa untuk belajar sains mulai dari menemukan masalah sampai menggambarkan kesimpulan tentang masalah ilmiah (Hofstein, 2005). Dengan menerapkan model pembelajaran kontekstual, akan dikembangkan LKM dalam matakuliah kimia Anorganik sehingga diakhir perkuliahan mahasiswa diharapkan mampu mengaplikasikan prinsip-prisip reaksi kimia anorganik yang relevan dan bermanfaat dalam kehidupan sehari-hari. Model kontekstual atau media LKM berbasis kontekstual secara langsung melibatkan siswa dengan kegiatan-kegiatan bermakna yang membantu mereka menghubungkan kajiankajian akademik dengan situasi kehidupan nyata penemuan yang bermakna merupakan ide sentral dari kontekstual itu sendiri. Selain itu kontekstual bermaksud menyampaikan pesan yang menekankan pada beberapa criteria antara lain: 1) menghubungkan pengetahuan dan keterampilan, 2) mempelajari konsep-konsep abstrak dengan melakukan aktivitas-aktivitas yang praktis, dan 3) menghubungkan pelajaran sekolah dengan dunia nyata dalam kehidupan. Penekanan-penekanan tersebut menghimbau para pendidik untuk mengkaitkan kajian-kajian akademik dengan dunia nyata. (Johnson, 2002).

Dalam tiga tahun terakhir tim pengampu matakuliah, berupaya melaksanakan proses perkuliahan dengan melibatkan mahasiswa secara langsung untuk memperoleh berbagai informasi mengenai ruang lingkup materi perkuliahan. Mahasiswa sudah ditugaskan untuk mempersiapkan makalah secara berkelompok dan saat tatap muka di kelas dosen memberi kesempatan untuk mempresentasikan tugas dan berdiskusi dengan kelompok lain. Strategi yang diterapkan cukup efektif untuk mengaktifkan mahasiswa, namun dengan alokasi waktu tatap muka 3x 50 menit, mahasiswa belum dapat berlatih dalam merancang/mendesain percobaan yang merupakan implementasi dari teori-teori yang diperoleh selama perkuliahan. 
Tim pengampu matakuliah secara bersama-sama sebelumnya telah memfasilitasi mahasiswa dengan media LKM dalam pembelajaran akan tetapi LKM yang sudah digunakan dirasakan masih banyak kekuranganl. Untuk itu perlu dilakukan pengembangan perangkat LKM dengan mengacu pada metode penelitian pengembangan yang akan digunakan untuk menghasilkan produk tertentu dan menguji efektifitasnya (Sugiyono, 2008). Pada tahap ini tim pengampu matakuliah kimia anorganik bermaksud untuk menghasilkan perangkat LKM . Pengembangan LKM dilakukan sampai tahap mengembangkan produk awal (Develop preliminary form of product).Langkah penelitian ini mengacu pada strategi yang dikembangkan oleh Borg and Gall (2010).

Penelitian ini bertujuan untuk mengembangkan perangkat pembelajaran yakni LKM berbasis kontekstual yang dipersiapkan untuk pelaksanaan matakuliah Kimia Anorganik berupa prototipe LKM yang praktis dan valid akan divalidasi secara internal dan siap untuk diujicobakan.

\section{METODE PENELITIAN}

Penelitian pengembangan mengacu kepada metode penelitian pengembangan( Sugiyono, 2008 ; Borg and Gall, 2010) bertujuan untuk mengembangkan dan menghasilkan prototype perangkat pembelajaran berupa LKM yang valid dan praktis , diujicoba dan diimplementasikan dalam perkuliahan .

Pembuatan dan pengembangan LKM didasarkan pada materi ajar dan model pembelajaran yang akan diterapkan. LKM yang dibuat dirinci untuk satu semester atau 16 minggu pertemuan, akan tetapi yang dihasilkan pada penelitian ini ada 4 buah LKM untuk 4 kali tatap muka efektif..

Tahapan penelitian adalah analisis awal sesuai dengan materi perkuliahan, dilanjutkan membuat draft LKM. LKM akan divalidasi secara internal oleh tim pengampu matakuliah dengan menggunakan lembar validasi yang telah disusun peneliti berpedoman kepada aspek-aspek yang divalidasi antara lain kerelevanan dengan peserta didik,, keilmiahan dalam segi isi, fleksibel, sistematis dan kesesuaian dengan azas pembelajaran yang efektif Hasil dari validasi oleh pakar sesuai bidang ilmu (Dosen pengampu matakuliah yang sama) merupakan data dari penelitian yang dapat digunakan sebagai pedoman perbaikan perangkat pembelajaran (LKM) yang dirancang sesuai 
kriteria yang ditentukan Hasil yang telah direvisi akan diujicobakan pada penelitian berikutnya.

\section{HASIL DAN PEMBAHASAN}

Penelitian telah dilaksanakan di FKIP Universitas Riau mulai bulan Juli hingga Desember 2014. Tahap pertama, tim peneliti mengumpulkan bahan ajar dan literatur. Thap selanjutnya adalah pembuatan LKM kontekstual dan validasi oleh validator.

Validasi LKM berbasis kontekstual dil oleh dua orang validator teman sejawat. Penelaahan LKM ditinjau dari segi aspek format, teknis dan isi. Hasil validasi terhadap aspek format, teknis dan isi dapat dilihat pada Tabel 1, Tabel 2 dan Tabel 3.

Tabel 1. Hasil Penilaian Format LKM

\begin{tabular}{|c|c|c|c|c|}
\hline \multirow{2}{*}{ No } & \multirow[t]{2}{*}{ Indikator Penilaian Format } & \multicolumn{3}{|c|}{ Penilaian Validator } \\
\hline & & Ada & Tidak & $\begin{array}{l}\text { Catatan } \\
\text { Perbaikan }\end{array}$ \\
\hline 1 & Judul & $\mathrm{X}$ & & \\
\hline 2 & Mencantumkan Tujuan & $\mathrm{x}$ & & \\
\hline 3 & Teori Singkat & $\mathrm{x}$ & & \\
\hline 4 & $\begin{array}{l}\text { Rumusan masalah/hipotesis/ } \\
\text { variable/devinisi operasional/table } \\
\text { data/analisis/kesimpulan. } \\
\text { Penerapan (jika ada) }\end{array}$ & $\mathrm{x}$ & & \\
\hline 5 & Langkah kerja & $\mathrm{X}$ & & \\
\hline 6 & Pertanyaan & $\mathrm{X}$ & & \\
\hline 7 & Daftar Pustaka & $\mathrm{x}$ & & \\
\hline
\end{tabular}

Tabel 2. Hasil Penilain Teknis LKM Anorganik

\begin{tabular}{llcc}
\hline \multirow{2}{*}{ No } & \multicolumn{1}{c}{ Indikator Penilaian } & \multicolumn{2}{c}{ Nilai rata-rata Validator } \\
\cline { 3 - 4 } & \multicolumn{2}{c}{$\begin{array}{l}\text { Sebelum } \\
\text { validasi }\end{array}$} & $\begin{array}{c}\text { Sesudah } \\
\text { validasi }\end{array}$ \\
\hline 1 & Ditulis menggunakan huruf cetak & 4 & 4 \\
\hline 2 & $\begin{array}{l}\text { Huruf untuk topik dengan } \\
\text { informasi/instruksi sudah dibedakan }\end{array}$ & 4 & 3.5 \\
\hline 3 & $\begin{array}{l}\text { Menggunakan tidak lebih dari 10 kata dalam } \\
\text { satu baris. Saran. Tuliskan informasi yang } \\
\text { penting saja }\end{array}$ & 32 & 4 \\
\hline 4 & $\begin{array}{l}\text { Pertanyaan yang diajukan menggiring } \\
\text { mahasiswa untuk bekerja sama menemukan } \\
\text { jawaban }\end{array}$ & 3.4 & 3.6 \\
\hline 5 & $\begin{array}{l}\text { Sajian LKM sudah membawa mahasiswa } \\
\text { dalam kehidupan nyata }\end{array}$ & 3.2 & 3 \\
\hline
\end{tabular}


Table 3. Hasil Penilaian Isi LKM Anorganik

\begin{tabular}{|c|c|c|c|}
\hline \multirow[b]{2}{*}{ No } & \multirow[b]{2}{*}{ Indikator Penilaian } & \multicolumn{2}{|c|}{ Nilai rata-rata Validator } \\
\hline & & $\begin{array}{c}\text { Sebelum } \\
\text { validasi }\end{array}$ & $\begin{array}{l}\text { Sesudah } \\
\text { validasi }\end{array}$ \\
\hline 1 & $\begin{array}{l}\text { Dapat digunakan mahasiswa } \\
\text { dengan } \\
\text { kecepatan bervariasi }\end{array}$ & 3 & 3 \\
\hline 2 & $\begin{array}{l}\text { Memuat langkah dan materi nyata } \\
\text { dalam kehidupan sehari-hari }\end{array}$ & 3 & 4 \\
\hline 3 & $\begin{array}{l}\text { Memberi kegiatan bervariasi } \\
\text { (baca, lakukan analisis, diskusi } \\
\text { dan menjawab) }\end{array}$ & 4 & 4 \\
\hline 4 & $\begin{array}{l}\text { Memberi kesempatan mencari/ } \\
\text { informasi berbeda }\end{array}$ & 4 & 4 \\
\hline 5 & $\begin{array}{l}\text { Kegiatan dapat mengembangkan } \\
\text { hubungan social, emosional }\end{array}$ & 4 & 4 \\
\hline 6 & $\begin{array}{l}\text { Bahasa yang digunakan sesuai } \\
\text { tingkat intelektual mahasiswa }\end{array}$ & 3 & 4 \\
\hline 7 & $\begin{array}{lcc}\text { Kalimat yang } & \text { digunakan } \\
\text { sederhana dan jelas } & \end{array}$ & 4 & 4 \\
\hline 8 & $\begin{array}{l}\text { Tata urutan materi kuliah sudah } \\
\text { sesuai, materi yg disajikan terkait } \\
\text { dengan kehidupan }\end{array}$ & 3.5 & $3,, 5$ \\
\hline 9 & $\begin{array}{l}\text { Pertanyaan telah disusun untuk } \\
\text { dijawab dengan pengolahan } \\
\text { informasi }\end{array}$ & 3.5 & 4 \\
\hline 10 & $\begin{array}{l}\text { Telah menyediakan kolom yang } \\
\text { cukup untuk menuliskan jawaban }\end{array}$ & 4 & 4 \\
\hline
\end{tabular}

Pada penilaian format semua aspek sudah terpenuhi sesuai kriteria yang dipedomani seperti pada Tabel 1. Lima aspek indikator penilaian teknis seperti pada Table 2. Empat aspek indikator diantaranya sudah pada kategori penilaian maksimal akan tetapi untuk aspek "Menggunakan tidak lebih dari 10 kata dalam satu baris, masih standar nilai 3.5, walau sudah diberi saran untuk menuliskan informasi yang penting saja. Gambar dan pertanyaan yang disajikan sudah mulai menempatkan mahasiswa ke dalam proses inquiri, tampilan LKM membuat mahasiswa seolah berada dalam kehidupan nyata 
Untuk penilaian Isi sesuai Table 3, memperoleh nilai rata-rata 3.85. LKM sudah dapat digunakan mahasiswa dengan kecepatan yang bervariasi, belum sepenuhnya memuat langkah untuk menunjang kontekstual akan tetapi sudah memberikan kegiatan bervariasi ( baca, diskusi, menjawab/ melakukan).

LKM dapat memberi kesempatan mencari informasi berbeda karena dalam instruksi melakukan kegiatan, meminta mahasiswa untuk membaca makalah dan sumber lain seperti internet, menghendaki kreativitas mahasiswa karena LKM menuntut agar mahasiswa sebelum percobaan perlu menganalisis alat dan bahan yang tersedia bertujuan mengarahkan mahasiswa untuk lebih professional. Kegiatan dapat mengembangkan hubungan sosial, emosional karena pada proses penggunaan LKM dilakukan secara berkelompok, dan bahasa yang digunakan sesuai tingkat intelektual mahasiswa. Kalimat sederhana dan jelas, Tata urutan materi belum sepenuhnya sesuai tingkat intelektual mahasiswa, masih dipandang perlu membahas materi dasar karena dibutuhkan mahasiswa di sekolah tempat mereka bekerja. Pertanyaan telah disusun untuk dijawab dengan pengolahan informasi, Sumber belajar terjangkau, rata-rata materi yang diperlukan mudah didapat. LKM dirancang sedemikian rupa dan sudah menyediakan kolom tempat mahasiswa menuliskan jawaban

\section{KESIMPULAN}

Berdasarkan pembahasan yang telah dikemukakan dapat disimpulkan bahwa LKM berbasis kontekstual yang dikembangkan untuk pembelajaran kimia anorganik memenuhi kriteria valid dari segi format, teknis maupun isi dan disarankan untuk mengujicobanya di kelas untuk melihat praktikalitas dan efektifitas perangkat yang dikembangkan.

\section{DAFTAR PUSTAKA}

Borg,W.R and Gall.M.D. 2010. Applying Educational Research. New York. Longman. Pearson

Cotton. A dan Wilkinson G 2002, Kimia Anorganik Dasar UI PRESS

Depdiknas 2003 Kurikulum 2004 SMA, Pedoman Khusus Pengembangan Silabus dan Penilaian Mata Pelajaran Kimia Jakarta

Fenrich, Peter. (1997). Practical Guidelines for Creating Instructinal Multimedia Aplication. Fort Worth: The Dryden Press Harcourt Cllege Publishers.

Jhonson, Elaine B. (2002). Contextual Teaching and Learning. Thausand aks, California: Crwin Press. 
Muhammad Muslich, 2008. KTSP Pembelajaran Berbasis Kompetensi dan Kontekstual, Jakarta: Bumi Aksara

Muhammad Nur, 2000, Buku Panduan Keterampilan Proses dan Hakikat Sains, UNESA, Surabaya

Muhammad Nur, 2000, Pengajaran Berpusat Pada Sisiwa dan Pendekatan Konstruktivistik Dalam Pengajaran, UNESA Surabaya

Muhammad Ramli, 2006,Karakter Kurikulum Berbasis Kompetensi, Makalah disajikan pada Seminar Internasional. Pendekatan PembelajaranTerkini untuk mewujudkan Pencapaian kompetensi dan Mutu Pendidikan oleh FKIP UNRI pada 10 Agustus 2006.

Suhadi, 2006 Menyikapi KTSP Tantangan Untuk Penyelenggaraan Pembelajaran yang lebih baik. Jurnal Pendidikan Inovatif Vol 2 Hal. 236-242

Sugiyono. 2008. Metode Penelitian Pendidikan, Pendekatan Kualitatif dan kuantitatif dan R \& D. Bandung. Alfabeta.

Thiagarajan, Semmel, Semmel, 1974, Instructional Development for Training Teachers of Exceptional Children. A Source Book, Blomington center of Inovasion on Teachin The Hondicapped Minneapolis Indiana Univercity

Warf, J C,2006 Dasar-Dasar Kimia Anorganik, Universitas Andalas Padang

Wina Sanjaya 2008 Kurikulum dan Pembelajaran Teori dan Praktek Pengembangan KTSP, Jakarta: Kencana Pranada Media Group 